\title{
Depression and family support in breast cancer patients
}

\author{
This article was published in the following Dove Press journal: \\ Neuropsychiatric Disease and Treatment \\ 13 September 2017 \\ Number of times this article has been viewed
}

\begin{abstract}
Jian-An Su, ${ }^{1-3, *}$ DahCherng Yeh, ${ }^{4, *}$ ChingChi Chang, ${ }^{5, *}$ Tzu-Chin Lin, ${ }^{6,7}$ Ching-Hsiang Lai, ${ }^{8}$ Pei-Yun $\mathrm{Hu},{ }^{8}$ Yi-Feng Ho, ${ }^{9}$ Vincent Chin-Hung Chen, ${ }^{1,2}$ Tsu-Nai Wang, ${ }^{10,11}$ Michael Gossop ${ }^{12}$
\end{abstract}

'Chang Gung Medical Foundation, Chiayi Chang Gung Memorial Hospital, Chiayi, Taiwan; ${ }^{2}$ Department of Medicine, School of Medicine, Chang Gung University, Taoyuan, Taiwan; ${ }^{3}$ Department of Nursing, Chang Gung Institute of Technology, Taoyuan,

Taiwan; ${ }^{4}$ Department of Surgery, Taichung Tzu Chi Hospital, Buddhist Tzu Chi Medical Foundation, Taichung, Taiwan; ${ }^{5}$ Institute of Medicine, Chung Shan Medical University and Department of Psychiatry, Chung Shan Medical University Hospital, Taichung, Taiwan; ${ }^{6}$ Department of Psychiatry, Chung Shan Medical University Hospital, Taichung, Taiwan; ${ }^{7}$ Department of Psychiatry, School of Medicine, Chung Shan Medical University, Taichung, Taiwan; ${ }^{8}$ Department of Medical Informatics, Chung Shan Medical University, Taichung, Taiwan; ${ }^{9} \mathrm{~T}$ saotun Psychiatric Center, Ministry of Health and Welfare, Nan-Tou, Taiwan; ${ }^{10}$ Department of Public Health, College of Health Science, Kaohsiung Medical University, Kaohsiung, Taiwan; "Center of Excellence for Environmental Medicine, Kaohsiung Medical University, Kaohsiung, Taiwan; ${ }^{12}$ King's

College London, Institute of Psychiatry, London, UK

*These authors contributed equally to this work

Correspondence: Tsu-Nai Wang Department of Public Health, College of Health Science, Kaohsiung Medical University, No 100, Shi-Chuan Ist Rd, Kaohsiung 807, Taiwan Tel $+88673|2|$ I0I ext $2|4|$

Fax +88673110811

Email wangtn@kmu.edu.tw
Background: Breast cancer is the most common cancer in women. Among the survivors, depression is one of the most common psychiatric comorbidities. This paper reports the point prevalence of major depressive disorder among breast cancer patients and the association between family support and major depressive disorder.

Methods: Clinical data were collected from a breast cancer clinic of a general hospital in central Taiwan. Participants included 300 patients who were older than 18 years and diagnosed with breast cancer. Among these individuals, we used Mini International Neuropsychiatric Interview (a structural diagnostic tool for psychiatric disorders) to ascertain if they had major depressive disorder. We also used the Family Adaptability, Partnership, Growth, Affection, and Resolve score to assess the family support.

Results: The point prevalence of major depressive disorder among breast cancer patients was $8.33 \%$, and this was positively associated with insomnia, psychiatric family history, pain severity, and radiotherapy and negatively associated with menopause, cancer duration, hormone therapy, and family support. Family support (adjusted odds ratio $=0.87,95 \%$ CI: $0.78-0.98$ ) was found to be an associated factor for major depressive disorder in breast cancer patients after controlling for potential risk factors.

Conclusion: Major depressive disorder is a common comorbidity among breast cancer patients. Family support is an important associated factor for these patients. Health care professionals should evaluate mood problems and family support while treating these patients.

Keywords: breast cancer, prevalence, depression, family support, risk factors, psychiatric disorders

\section{Introduction}

Breast cancer is the most common cancer in women. It is also one of the leading causes of cancer death worldwide. ${ }^{1}$ With early diagnosis and treatment, the 5 -year survival rate of breast cancer is $89 \%$. $^{2}$ However, the peak incidence of breast cancer falls in middle age. The patients usually play an important role either in families or in societies at the time that the diagnosis of breast cancer is given. ${ }^{3}$ Thus, the impact of breast cancer is significant physically, mentally, and socially.

It has been reported that many breast cancer patients experience great stress during the course of treatment. Fear, worry, anger, uncertainty for the future, and body image concern are common responses. ${ }^{4-6}$ Depression is one of the most common psychiatric diagnoses in breast cancer survivals. The prevalence of depression ranges from $5 \%$ to $40 \%$, and most studies report rates between $10 \%$ and $25 \% .{ }^{7,8}$ In addition, the side effects of long-term hormone therapy or chemotherapy, such as menopause, pain, and insomnia may also lead to depression. ${ }^{9,10}$ Depression can worsen the feeling of discomfort and may result in poorer outcome. ${ }^{11-14}$ Persistent depression has 
been found to be associated with poorer cognition, family function, treatment compliance, greater physical distress, and more use of tobacco or alcohol, which decreased the quality of life. ${ }^{15-17}$

Several risk factors for depression in breast cancer patients have been reported such as being single, divorced, sleep disturbance, past history of depression, pain, neuroticism, and stressful life events. ${ }^{18-24}$ The roles of smoking, alcohol drinking, or exercise still remain unclear. Family support and social support are both important protective factors for depressive patients in the general population. ${ }^{25}$ Family members are also affected by the changes experienced by the patient and must adjust to new roles in the cancer journey. ${ }^{26,27}$ Maly et al indicated that breast cancer patients with higher family support had less depressive or anxiety symptoms. ${ }^{28}$ It has also been reported that mental support and empathy from the spouse were related to lower depressive symptoms among elderly breast cancer survivals. ${ }^{29}$ Another study focusing on younger breast cancer patients pointed to the importance of family support after the diagnosis of breast cancer. ${ }^{30}$ However, research into the relationship of family support and depression was limited in Asia.

The aim of our study was to investigate the point prevalence of depression and the comprehensive risk factors among depression and breast cancer. In contrast to previous studies, we used Mini International Neuropsychiatric Interview (MINI), a structural diagnostic tool, to diagnose depression instead of evaluating the symptoms of depression by rating scales only.

\section{Methods \\ Study design}

This is a cross-sectional study that was carried out in a general hospital between October 2011 and September 2012. The potential participants were all breast cancer patients who attended the general hospital for cancer routine treatment. We initially included patients older than 18 years with first diagnosis of breast cancer. Those who could not sign informed consent, individuals with intellectual disability or dementia were not invited for participation. The medical information we collected included three parts: 1) medical records including cancer staging and treatments (eg, operation, radiation therapy, chemotherapy, hormone therapy, targeted therapy); 2) assessment of psychiatric diagnosis by MINI and family support by Family Adaptability, Partnership, Growth, Affection, and Resolve (APGAR) score; and 3) demographic data, marital status, duration of breast cancer, exercising, psychiatric history, sleep condition, sleeping pill use, substance use, pain severity by visual analog scale (VAS), and psychiatric family history. The study was approved by the institutional review board of Taichung Veterans General Hospital.

\section{Assessment tools}

MINI is a structural diagnostic interview tool that was developed by Sheehan for Diagnostic and Statistical Manual of Mental Disorders, 4th Edition psychiatric diagnosis. ${ }^{31}$ The Chinese version of MINI was used in other research in Taiwan. ${ }^{32}$ In the present study, the section of major depressive disorder in MINI was administered by a trained researcher.

Smilkstein's Family APGAR score was developed in 1978 and consisted of five questions for quantifying the perception of family functionality. ${ }^{33}$ The assessment of the individual's satisfaction with their family functioning is based on the five parameters: adaptability, partnership, growth, affection, and resolve. The response options were designed to describe frequency of feeling satisfied with each parameter on a 3-point scale ranging from 0 (hardly ever) to 2 (almost always) and higher score means higher family support and functionality.

The VAS of pain provides a simple technique for measuring subjective pain and has been found to be a valid and reliable tool in a range of clinical and research applications. ${ }^{34}$ It is a graphic tool with a $100 \mathrm{~mm}$ horizontal line with the left end marked as "no symptom" and the right end marked as "worst imaginable symptom." The patient is asked to draw a vertical line to indicate the horizontal scale at a point that corresponds to the intensity of pain. The length from the left end to the vertical mark made by the patient is measured in millimeters.

\section{Statistical analysis}

The $\chi^{2}$ - and unpaired $t$-tests were used to evaluate percentage and mean differences between MINI responders and nonresponders in terms of basic demographic characteristics, medical information, and family support score. We also compared the prevalence of major depression in different subgroups. Pain severity, Family APGAR score, and the associated factors showed statistical significance between the two groups were included in further logistic regression analyses. Unadjusted and adjusted logistic regressions were further used to determine the significance of association. A $p$-value of $<0.05$ was used to indicate statistical significance.

\section{Results}

We screened 465 potential breast cancer patients for eligibility. A total of 451 eligible breast cancer patients were 
invited to participate in this study and completed the basic assessment including demographic data, medical records, life style, and Family APGAR score. Furthermore, 300 patients agreed to have assessment of psychiatric diagnosis by MINI. The protocol for participant selection is shown in Figure 1. The overall response rate is $66.5 \%(300 / 451)$. In Table 1, there was no difference for the age distribution, marital status, occupation, cigarette smoking, alcohol drinking, exercising habit, cancer stage, pain severity, and family support score between MINI responders and non-responders. All of them were female patients, and the mean age of responders was $48.16 \pm 9.07$ years. Half (50.3\%) of the responders had been diagnosed with breast cancer within the past year. The mean duration of cancer diagnosis was $2.0 \pm 2.7$ years. More than $90 \%$ were in stage I-III, and surgery was the most common treatment option $(82.3 \%)$. Other treatments included radiotherapy $(58.7 \%)$, chemotherapy $(71.7 \%)$, hormone therapy (70\%), and target-drug therapy (22.7\%). Twenty-five patients met the criteria for a current major depressive disorder by MINI, and the overall prevalence was $8.33 \%$.

Data and comparisons of the prevalence of major depressive disorder in different subgroups are shown in Table 2. Insomnia, taking sleeping pills, positive psychiatric family history, chronic pain in the previous 1-year period, shorter breast cancer duration ( $<1$ year), radiation therapy, and without hormone therapy were related to higher prevalence

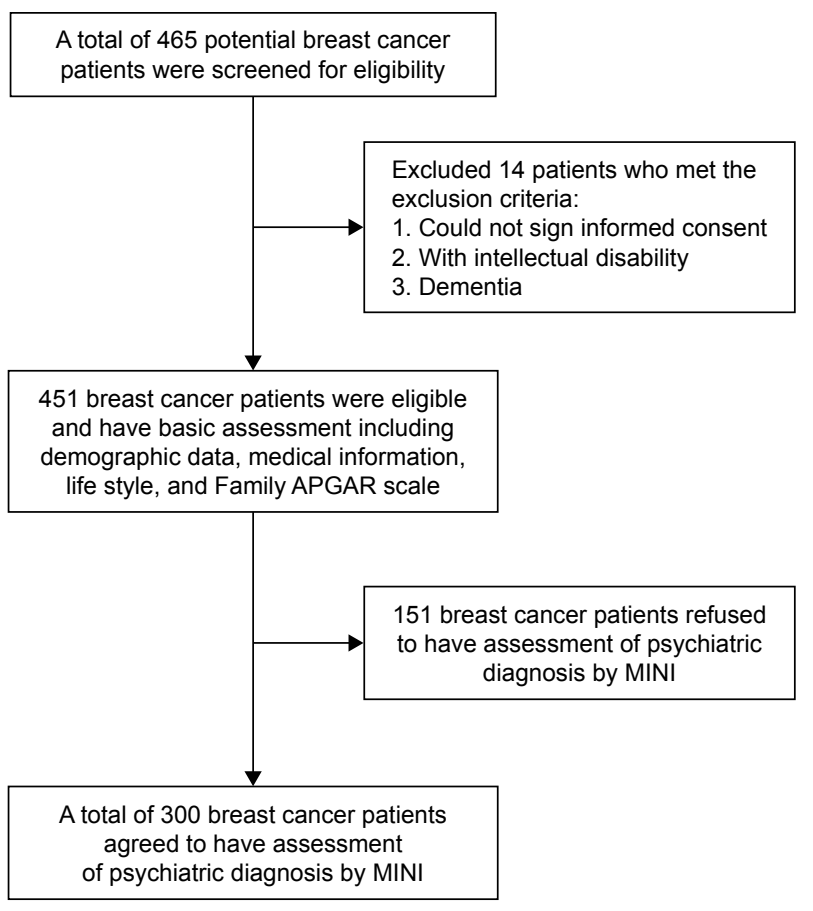

Figure I Flowchart for participant selection.

Abbreviations: APGAR, Adaptability, Partnership, Growth, Affection, and Resolve; MINI, Mini International Neuropsychiatric Interview. of major depressive disorder. However, treatment for operation, target-drug therapy, and different cancer stage did not show a difference in prevalence. In addition, we also compared the Family APGAR score and pain severity score between those with and without major depression. The result showed that those without major depression had better family support $(p<0.001)$ and higher pain severity score $(p<0.001)$.

Family APGAR score, pain severity score, and the factors that were statistically significant in Table 2 were included in the regression model. The associations as shown by unadjusted and adjusted logistic regression analyses are shown in Table 3. In the unadjusted model, insomnia, pain severity, and undergoing radiation therapy were associated with higher risks for major depressive disorder. On the other hand, longer duration of breast cancer, menopause, hormone therapy, and higher family support were associated with lower risks for major depressive disorder. In the final adjusted model, it was found that pain severity and undergoing radiotherapy were associated with higher risks for major depressive disorder. Higher family support and hormone therapy were associated with lower risks for major depressive disorder.

\section{Discussion}

In our study, the prevalence of major depressive disorder among breast cancer patients was $8.33 \%$. This was related to pain severity, radiotherapy, hormone therapy, and family support. The results also showed that family support was an associated factor for major depressive disorder among breast cancer patients.

A meta-analysis by Zainal et al included 10,826 breast cancer patients from 32 research studies and found that the incidence of depressive disorder varied from $1 \%$ to $56 \% .^{35}$ The median prevalence differed when using different diagnostic tools: $22 \%$ (13\% to $56 \%$ ) with Center of Epidemiologic Studies Depression, 22\% (17\% to 48\%) with Beck Depression Index, and $10 \%$ ( $1 \%$ to $22 \%$ ) with the Hospital Anxiety Depression Scale. In five other studies that used a structural diagnostic interview tool (Structural Clinical Interview for Diagnostic Statistical Manual), the mean prevalence was $16.25 \%$ (9\% to $25 \%)$. ${ }^{35}$ The prevalence of major depressive disorder in our study $(8.33 \%)$ was lower than that in the studies mentioned above. In previous studies, the prevalence of depression has been found to be lower in Asia than in Western countries. ${ }^{36,37}$ Andrade et al studied the prevalence of major depressive episode in ten countries and reported that it was lower in Turkey and Japan compared to other countries in Europe or America. ${ }^{36}$ In another epidemiological study in Taiwan by Hwu et al, lower prevalence of major depressive 
Table I Baseline characteristics of breast cancer patients between MINI responders and non-responders

\begin{tabular}{|c|c|c|c|c|c|}
\hline Characteristics & $\begin{array}{l}\text { MINI responders } \\
(\mathrm{N}=300)^{*}\end{array}$ & (\%) & $\begin{array}{l}\text { Non-responders } \\
(n=15 I)\end{array}$ & (\%) & $p$-value \\
\hline Age (mean SD) & 48.16 & 9.07 & 48.85 & 7.87 & 0.43 \\
\hline $18-40$ years & 63 & $(21.0)$ & 22 & $(14.5)$ & 0.24 \\
\hline $4 I-54$ years & 171 & (57.0) & 91 & $(60.3)$ & \\
\hline$\geq 55$ years & 66 & $(22.0)$ & 38 & $(25.2)$ & \\
\hline \multicolumn{6}{|l|}{ Marriage } \\
\hline Yes & 225 & $(75.3)$ & 111 & $(74.0)$ & 0.86 \\
\hline No & 74 & $(24.7)$ & 39 & $(26.0)$ & \\
\hline \multicolumn{6}{|l|}{ Occupation } \\
\hline Yes & 125 & $(4 \mid .8)$ & 70 & $(46.7)$ & 0.38 \\
\hline No & 174 & (58.2) & 80 & (53.3) & \\
\hline \multicolumn{6}{|l|}{ Cigarette smoking } \\
\hline Yes & 29 & $(9.7)$ & 9 & $(6.0)$ & 0.24 \\
\hline No & 270 & $(90.3)$ & 142 & $(94.0)$ & \\
\hline \multicolumn{6}{|l|}{ Alcohol drinking } \\
\hline Yes & 101 & (33.9) & 51 & (33.8) & 1.00 \\
\hline No & 197 & $(66.1)$ & 100 & $(66.2)$ & \\
\hline \multicolumn{6}{|l|}{ Regular exercise } \\
\hline Yes & 172 & (57.5) & 80 & $(53.0)$ & $0.4 \mathrm{I}$ \\
\hline No & 127 & $(42.5)$ & 71 & $(47.0)$ & \\
\hline \multicolumn{6}{|l|}{ Insomnia } \\
\hline Yes & 119 & (39.8) & 65 & $(43.0)$ & 0.58 \\
\hline No & 180 & $(60.2)$ & 86 & (57.0) & \\
\hline \multicolumn{6}{|l|}{ Stage } \\
\hline I-III & 249 & $(96.5)$ & 122 & $(97.6)$ & 0.79 \\
\hline IV & 9 & $(3.5)$ & 3 & $(2.4)$ & \\
\hline Pain severity score (SD) & 1.50 & 2.22 & 1.73 & 2.35 & 0.33 \\
\hline Family APGAR score (SD) & 9.93 & 3.87 & 9.95 & 3.85 & 0.96 \\
\hline
\end{tabular}

Note: *Missing data excluded.

Abbreviations: SD, standard deviation; MINI, Mini International Neuropsychiatric Interview; APGAR, Adaptability, Partnership, Growth, Affection, and Resolve.

disorder was reported in Taiwan than in the United States or Korea ${ }^{37}$ A possible explanation might be that this reflects cultural variance and/or other ethnic differences. In addition, different study designs, cancer stages, and illness duration may lead to different prevalence rates.

With regard to the association between marital status and depression, findings tend to be inconsistent. ${ }^{35}$ Some studies showed that being single or divorced was more likely to be associated with depressive disorder. ${ }^{18,19}$ However, Pumo et al reported that married breast cancer patients had higher prevalence of depression..$^{38}$ In our study, marital status had no significant relationship with major depressive disorder in final logistic regression analysis. It is possible that the number of depressed patients was too small to show any statistical difference.

In terms of the association between different treatment interventions and depression, some studies found that depression was more likely in patients undergoing chemotherapy ${ }^{18,39}$ or radiation therapy ${ }^{40-42}$ Another study indicated that those who had received prior chemotherapy were more likely to be depressed after radiation therapy but that radiation therapy alone did not increase the depressive symptoms ${ }^{43}$ Our study showed that patients who received radiation therapy had significantly higher risks for depression. Radiotherapy is predominantly provided in breast cancer with poorer prognosis, and this possibly explains part of the association with depression. On the other hand, hormone treatment provided for hormone receptor-positive tumors are generally associated with better prognosis than hormone receptor-negative tumors. Thus, the incidence of depression is lower. Moreover, we did not consider the effects of combined treatment regimens, and the tolerability of chemotherapy and radiation therapy varied in different ethnic groups. Further prospective, longitudinal studies are needed to confirm the relationship of different treatment and depression.

Family support is an important factor in breast cancer patients, and our results showed that higher family support was associated with lower risk for depression. A prospective study following the patients for 23 years also reported that higher family support was related to lower levels of depression at baseline and quicker improvement of depression. ${ }^{25}$ Support from the spouse is especially important. A previous 
Table 2 Prevalence of major depression based on risk factors in breast cancer patients $(\mathrm{N}=300)$

\begin{tabular}{|c|c|c|c|c|c|}
\hline Variables & Group & $\begin{array}{l}\text { Major depression/ } \\
\text { total number }\end{array}$ & Prevalence (\%) & $95 \% \mathrm{Cl}(\%)$ & $p$-value \\
\hline Total patients & & $25 / 300$ & 8.33 & $5.21-11.46$ & \\
\hline \multicolumn{6}{|l|}{ Basic characteristics } \\
\hline \multirow[t]{3}{*}{ Age } & $18-40$ years & $8 / 63$ & 12.7 & $4.48-20.9$ & 0.343 \\
\hline & $4 I-54$ years & $|3 / 17|$ & 7.60 & $3.63-11.6$ & \\
\hline & $\geq 55$ years & $4 / 66$ & 6.06 & $0.31-11.8$ & \\
\hline \multirow[t]{2}{*}{ Marriage } & No & $6 / 74$ & 8.11 & $1.89-14.3$ & 0.928 \\
\hline & Yes & $19 / 225$ & 8.44 & $4.8 I-12.1$ & \\
\hline \multirow[t]{2}{*}{ Cigarette smoking } & No & $22 / 270$ & 8.15 & $4.88-11.4$ & 0.793 \\
\hline & Yes & $3 / 29$ & 10.3 & $0.0-21.4$ & \\
\hline \multirow[t]{2}{*}{ Alcohol drinking } & No & $18 / 197$ & 9.14 & $5.11-13.2$ & 0.515 \\
\hline & Yes & $7 / 101$ & 6.93 & $1.98-11.9$ & \\
\hline \multirow[t]{2}{*}{ Regular exercise } & Yes & $11 / 172$ & 6.40 & $2.74-10.1$ & 0.153 \\
\hline & No & $14 / 127$ & 11.0 & $5.58-16.5$ & \\
\hline \multicolumn{6}{|l|}{ Psychosocial factors } \\
\hline \multirow[t]{2}{*}{ Insomnia } & Yes & $16 / 119$ & 13.5 & $7.32-19.6$ & 0.010 \\
\hline & No & $9 / 180$ & 5.00 & $1.81-8.18$ & \\
\hline \multirow[t]{2}{*}{ Taking sleeping pills } & Yes & $8 / 47$ & 17.0 & $6.28-27.8$ & 0.019 \\
\hline & No & $17 / 252$ & 6.75 & $3.65-9.84$ & \\
\hline \multirow[t]{2}{*}{ Psychiatric family history } & Yes & $6 / 27$ & 22.2 & $6.54-37.9$ & 0.006 \\
\hline & No & $19 / 254$ & 7.48 & $4.25-10.7$ & \\
\hline \multirow[t]{2}{*}{ Chronic pain within one year } & Yes & $14 / 84$ & 16.7 & $8.70-24.6$ & 0.001 \\
\hline & No & $11 / 215$ & 5.12 & $2.17-8.06$ & \\
\hline \multicolumn{6}{|l|}{ Cancer related factors } \\
\hline \multirow[t]{2}{*}{ Menopause } & Yes & $10 / 180$ & 5.60 & $2.21-8.90$ & 0.031 \\
\hline & No & $15 / 119$ & 12.6 & $6.64-18.6$ & \\
\hline \multirow[t]{2}{*}{ Duration of breast cancer } & $\leq$ I year & $18 / 150$ & 12.0 & $6.80-17.2$ & 0.012 \\
\hline & $>$ I year & $6 / 148$ & 4.05 & $0.88-7.23$ & \\
\hline \multirow[t]{2}{*}{ Stage of cancer } & I-III & $20 / 249$ & 3.4 & $1.15-5.65$ & 0.540 \\
\hline & IV & $1 / 9$ & 4.8 & $-9.17-18.8$ & \\
\hline \multicolumn{6}{|l|}{ Treatments } \\
\hline \multirow[t]{2}{*}{ Operation } & Yes & $21 / 247$ & 8.50 & $5.02-12.0$ & 0.819 \\
\hline & No & $4 / 53$ & 7.55 & $0.44-14.7$ & \\
\hline \multirow[t]{2}{*}{ Radiation therapy } & Yes & $20 / 176$ & 11.36 & $6.67-16.1$ & 0.024 \\
\hline & No & $5 / 124$ & 4.03 & $0.57-7.49$ & \\
\hline \multirow[t]{2}{*}{ Hormone therapy } & Yes & $13 / 210$ & 6.19 & $2.93-9.45$ & 0.040 \\
\hline & No & $12 / 90$ & 13.33 & $6.31-20.4$ & \\
\hline \multirow[t]{2}{*}{ Chemotherapy } & Yes & $20 / 215$ & 9.30 & $5.42-13.2$ & 0.334 \\
\hline & No & $5 / 85$ & 5.88 & $0.88-10.9$ & \\
\hline \multirow[t]{2}{*}{ Target-drug therapy } & Yes & $8 / 68$ & 11.7 & $4.11-19.4$ & 0.244 \\
\hline & No & $17 / 232$ & 7.33 & $3.97-10.7$ & \\
\hline
\end{tabular}

study reported that greater perceived support from the spouse was associated with lower levels of depression. ${ }^{29}$ Another study among breast cancer patients aged $\geq 55$ years revealed that support from adult children was also related to less anxiety and depression. ${ }^{28}$ Northouse et al found that family support had a positive impact on quality of life for both the patients and their families. ${ }^{44}$ However, similar studies on family support among breast cancer patients have been lacking in the Chinese population. Our study supported those previous findings that family support is also important for breast cancer patients in the Taiwanese and that family support helps to protect them from mood problems. For health professionals, it is important to understand family interactions during the course of the illness and to provide information about how to improve and maintain enough family support and functionality. In addition, patients with depression might tend to report feeling less supported by their family. However, our study is a cross-sectional study design, and further prospective cohort study is needed to explore the causal relation.

Pain, anxiety, and depression have been found to be inter-correlated in breast cancer patients. ${ }^{45} \mathrm{We}$ found that pain severity is associated with higher prevalence of depression. More than $80 \%$ of our participants underwent surgery. It has been reported that postoperative pain plays a role in 
Table 3 Logistic regression analyses of factors associated with major depression

\begin{tabular}{|c|c|c|c|c|c|}
\hline \multirow[t]{2}{*}{ Characteristic } & \multicolumn{5}{|c|}{$\begin{array}{l}\text { Associations with depression prevalence - odds ratios }(95 \% \mathrm{Cl}) \text { displayed for simultaneously } \\
\text { entered covariates }\end{array}$} \\
\hline & Unadjusted & Adjusted model Ia & Adjusted model $2^{\mathrm{b}}$ & Adjusted model $3^{c}$ & Final model $4^{d}$ \\
\hline Age, years & $0.96(0.92-1.01)$ & $0.96(0.92-1.01)$ & $0.98(0.92-1.05)$ & $0.98(0.92-1.05)$ & $0.96(0.9 \mathrm{I}-\mathrm{I} .0 \mathrm{I})^{+}$ \\
\hline \multicolumn{6}{|l|}{ Psychosocial factors } \\
\hline Insomnia (yes/no) & $2.95(1.26-6.92)^{*}$ & $2.38(0.97-5.89)^{+}$ & $2.22(0.87-5.65)^{+}$ & $2.44(0.94-6.36)^{+}$ & $2.01(0.78-5.15)$ \\
\hline Psychiatric family history (yes/no) & $3.81(1.37-10.6)^{*}$ & $2.13(0.7 I-6.43)$ & - & - & - \\
\hline Pain severity (score) & $1.29(1.11-1.50)^{* *}$ & $1.25(1.07-1.47)^{* *}$ & $1.32(1.12-1.57)^{* *}$ & $1.32(1.11-1.56)^{* *}$ & $1.27(1.08-1.49)^{* *}$ \\
\hline \multicolumn{6}{|l|}{ Cancer-related factors } \\
\hline Menopause (yes/no) & $0.4 \mathrm{I}(0.18-0.94)^{*}$ & - & $0.50(0.15-1.67)$ & $0.43(0.12-1.52)$ & - \\
\hline Duration of breast cancer (years) & $0.31(0.12-0.84)^{*}$ & - & $0.31(0.11-0.89)^{*}$ & $0.45(0.15-1.40)$ & - \\
\hline \multicolumn{6}{|l|}{ Treatment } \\
\hline Radiation therapy (yes/no) & $3.05(1.11-8.37)^{*}$ & - & - & $4.61(1.40-15.1)^{*}$ & $5.53(1.69-18.06)^{* *}$ \\
\hline Hormone therapy (yes/no) & $0.43(0.19-0.98)^{*}$ & - & - & $0.32(0.11-0.93)^{*}$ & $0.23(0.08-0.62)^{* *}$ \\
\hline Family support (score) & $0.84(0.75-0.93)^{* * *}$ & - & - & - & $0.87(0.78-0.98)^{*}$ \\
\hline
\end{tabular}

the development of chronic pain and depression. ${ }^{46}$ However, pain relief after cancer is sometimes suboptimal. ${ }^{47}$ Thus, in order to reduce the prevalence of depression in breast cancer patients, more aggressive pain control strategy is needed especially for those who underwent surgery.

Broeckel et al reported that longer periods after cancer diagnosis and chemotherapy completion were positively related to greater depressive symptoms. ${ }^{19}$ However, Khan et al found that recent diagnosis was associated with more severe depressive symptoms ${ }^{48}$ and that depression decreased with longer survival time. ${ }^{49}$ Our findings were consistent with those of the latter study. Cancer diagnosis within 1 year was associated with depression. Mullan in 1985 described the different stages in cancer journey. ${ }^{50}$ In the earlier stage, cancer patients underwent aggressive treatments, experienced high levels of emotional stress, and fear of potential death, and therefore depression is more likely possible at that time. In the later stage, it is described as a permanent survival phase which carries less stress in the fear of recurrence and that less depression is noted during that phase.

\section{Limitations}

There are still a number of limitations in our study. First, this is a cross-sectional study and thus cannot indicate the causal relationship of risk factors and depression. It needs further prospective cohort study to provide evidence of causal links. Second, the sample size and the number of depressive patients are small. It might be difficult to show the significance in statistical analyses. Furthermore, the response is rather low (66.5\%), and this might bias the estimated point prevalence of depression as well as the analyses of factors associated with depression. Third, we used only the section of major depressive disorder in MINI and did not rule out other psychiatric disorders such as schizophrenia or delusional disorder comorbidities with depression. Last, the study was carried out in a single general hospital; hence, generalization of our results to other hospital settings should be with caution.

\section{Conclusion}

The prevalence of major depressive disorder was $8.33 \%$ in breast cancer patients. This was associated with pain severity, radiation therapy, hormone therapy, and family support. In clinical practice, physicians should pay careful attention to those breast cancer patients with risk factors for depression. Timely intervention is needed for high-risk patients to reduce the impact of depression in breast cancer. In the future, further study can address on the possibility of reducing the depressive symptoms if enhancing the perceived family support.

\section{Acknowledgments}

The funding agencies had no role in the study design, data collection, data analysis, data interpretation, or writing of the report. This study was supported by grants from the National Science Council of Taiwan, grant no NSC 102-2632-B-037001-MY3, and partially from the Kaohsiung Medical University "Aim for the Top Universities Grant, grant No KMU-TP103A16, KMU-TP104A01." The abstract of this paper was presented at the 24th European Congress of Psychiatry, as a poster presentation with interim findings. The abstract of the poster was published in "Poster Abstracts" in 
European Psychiatry. Available from: http://www.europsyjournal.com/article/S0924-9338(16)00494-6/abstract.

\section{Disclosure}

The authors report no conflicts of interest in this work.

\section{References}

1. Ferlay J, Soerjomataram I, Dikshit R, et al. Cancer incidence and mortality worldwide: sources, methods and major patterns in GLOBOCAN 2012. Int J Cancer Suppl. 2015;136(5):E359-E386.

2. Society AC. Cancer Facts and Figures 2007. Atlanta: American Cancer Society; 2007.

3. Leong SP, Shen ZZ, Liu TJ, et al. Is breast cancer the same disease in Asian and Western countries? World J Surg. 2010;34(10):2308-2324.

4. Nelson JP. Struggling to gain meaning: living with the uncertainty of breast cancer. ANS Adv Nurs Sci. 1996;18(3):59-76.

5. van den Beuken-van Everdingen MH, Peters ML, de Rijke JM, Schouten HC, van Kleef M, Patijn J. Concerns of former breast cancer patients about disease recurrence: a validation and prevalence study. Psycho-oncology. 2008;17(11):1137-1145.

6. Carver CS, Pozo-Kaderman C, Price AA, et al. Concern about aspects of body image and adjustment to early stage breast cancer. Psychosom Med. 1998;60(2):168-174.

7. Fann JR, Thomas-Rich AM, Katon WJ, et al. Major depression after breast cancer: a review of epidemiology and treatment. Gen Hosp Psychiatry. 2008;30(2):112-126.

8. Reich M, Lesur A, Perdrizet-Chevallier C. Depression, quality of life and breast cancer: a review of the literature. Breast Cancer Res Treat. 2008;110(1):9-17.

9. Dodd MJ, Cho MH, Cooper BA, Miaskowski C. The effect of symptom clusters on functional status and quality of life in women with breast cancer. Eur J Oncol Nurs. 2010;14(2):101-110.

10. Tchen N, Juffs HG, Downie FP, et al. Cognitive function, fatigue, and menopausal symptoms in women receiving adjuvant chemotherapy for breast cancer. J Clin Oncol. 2003;21(22):4175-4183.

11. Longman AJ, Braden CJ, Mishel MH. Side-effects burden, psychological adjustment, and life quality in women with breast cancer: pattern of association over time. Oncol Nurs Forum. 1999;26(5):909-915.

12. Hermelink K, Kuchenhoff H, Untch M, et al. Two different sides of 'chemobrain': determinants and non-determinants of self-perceived cognitive dysfunction in a prospective, randomized, multicenter study. Psycho-oncology. 2010;19(12):1321-1328.

13. Eskelinen M, Korhonen R, Selander T, Ollonen P. Beck depression inventory as a predictor of long-term outcome among patients admitted to the breast cancer diagnosis unit: a 25-year cohort study in Finland Anticancer Res. 2017;37(2):819-824.

14. Eskelinen M, Selander T, Ollonen P, Korhonen R. Moderate/severe depression (MADRS) can affect the quality of life and outcome among patients admitted to breast cancer diagnosis unit. Anticancer Res. 2017; 37(5):2641-2647.

15. de Jong N, Candel MJ, Schouten HC, Abu-Saad HH, Courtens AM. Course of mental fatigue and motivation in breast cancer patients receiving adjuvant chemotherapy. Ann Oncol. 2005;16(3):372-382.

16. Ayres A, Hoon PW, Franzoni JB, Matheny KB, Cotanch PH, Takayanagi S. Influence of mood and adjustment to cancer on compliance with chemotherapy among breast cancer patients. J Psychosom Res. 1994;38(5):393-402.

17. Dorros SM, Card NA, Segrin C, Badger TA. Interdependence in women with breast cancer and their partners: an interindividual model of distress. J Consult Clin Psychol. 2010;78(1):121-125.

18. Morrill EF, Brewer NT, O'Neill SC, et al. The interaction of posttraumatic growth and post-traumatic stress symptoms in predicting depressive symptoms and quality of life. Psycho-oncology. 2008;17(9) 948-953.
19. Broeckel JA, Jacobsen PB, Balducci L, Horton J, Lyman GH. Quality of life after adjuvant chemotherapy for breast cancer. Breast Cancer Res Treat. 2000;62(2):141-150.

20. Chen X, Zheng Y, Zheng W, et al. Prevalence of depression and its related factors among Chinese women with breast cancer. Acta Oncol. 2009; 48(8):1128-1136.

21. Karakoyun-Celik O, Gorken I, Sahin S, Orcin E, Alanyali H, Kinay M. Depression and anxiety levels in woman under follow-up for breast cancer: relationship to coping with cancer and quality of life. Med Oncol. 2010;27(1):108-113.

22. Vahdaninia M, Omidvari S, Montazeri A. What do predict anxiety and depression in breast cancer patients? A follow-up study. Soc Psychiatry Psychiatr Epidemiol. 2010;45(3):355-361.

23. Ollonen P, Lehtonen J, Eskelinen M. Stressful and adverse life experiences in patients with breast symptoms: a prospective case-control study in Kuopio, Finland. Anticancer Res. 2005;25(1B):531-536.

24. Ollonen P, Lehtonen J, Eskelinen M. Anxiety, depression, and the history of psychiatric symptoms in patients with breast disease: a prospective case-control study in Kuopio, Finland. Anticancer Res. $2005 ; 25(3 \mathrm{c}): 2527-2533$.

25. Kamen C, Cosgrove V, McKellar J, Cronkite R, Moos R. Family support and depressive symptoms: a 23-year follow-up. J Clin Psychol. 2011; 67(3):215-223.

26. Bloom JR, Stewart SL, Johnston M, Banks P, Fobair P. Sources of support and the physical and mental well-being of young women with breast cancer. Soc Sci Med. 2001;53(11):1513-1524.

27. Coyne E, Borbasi S. Living the experience of breast cancer treatment: the younger women's perspective. Aust J Adv Nurs. 2009;26(4):6-13.

28. Maly RC, Umezawa Y, Leake B, Silliman RA. Mental health outcomes in older women with breast cancer: impact of perceived family support and adjustment. Psycho-oncology. 2005;14(7):535-545.

29. Talley A, Molix L, Schlegel RJ, Bettencourt A. The influence of breast cancer survivors' perceived partner social support and need satisfaction on depressive symptoms: a longitudinal analysis. Psychol Health. 2010;25(4):433-449.

30. Coyne E, Wollin J, Creedy DK. Exploration of the family's role and strengths after a young woman is diagnosed with breast cancer: views of women and their families. Eur J Oncol Nurs. 2012;16(2):124-130.

31. Sheehan DV, Lecrubier Y, Sheehan KH, et al. The Mini-International neuropsychiatric interview (M.I.N.I.): the development and validation of a structured diagnostic psychiatric interview for DSM-IV and ICD-10. J Clin Psychiatry. 1998;59 Suppl 20:22-33; quiz 34-57.

32. Chiang SC, Chan HY, Chang YY, Sun HJ, Chen WJ, Chen CK. Psychiatric comorbidity and gender difference among treatmentseeking heroin abusers in Taiwan. Psychiatry Clin Neurosci. 2007; 61(1):105-111.

33. Smilkstein G, Ashworth C, Montano D. Validity and reliability of the family APGAR as a test of family function. J Fam Pract. 1982;15(2): 303-311.

34. McCormack HM, Horne DJ, Sheather S. Clinical applications of visual analogue scales: a critical review. Psychol Med. 1988;18(4): 1007-1019.

35. Zainal NZ, Nik-Jaafar NR, Baharudin A, Sabki ZA, Ng CG. Prevalence of depression in breast cancer survivors: a systematic review of observational studies. Asian Pac J Cancer Prev. 2013;14(4):2649-2656.

36. Andrade L, Caraveo-Anduaga JJ, Berglund P, et al. The epidemiology of major depressive episodes: results from the International Consortium of Psychiatric Epidemiology (ICPE) Surveys. Int J Methods Psychiatr Res. 2003;12(1):3-21.

37. Hwu HG, Compton WM. Comparison of major epidemiological surveys using the diagnostic interview schedule. Int Rev Psychiatry. 1994;6(4): 309-327.

38. Pumo V, Milone G, Iacono M, et al. Psychological and sexual disorders in long-term breast cancer survivors. Cancer Manag Res. 2012;4:61-65.

39. Eversley R, Estrin D, Dibble S, Wardlaw L, Pedrosa M, Favila-Penney W Post-treatment symptoms among ethnic minority breast cancer survivors. Oncol Nurs Forum. 2005;32(2):250-256. 
40. Massie MJ. Prevalence of depression in patients with cancer. $J$ Natl Cancer Inst Monogr. 2004;(32):57-71.

41. Luutonen S, Vahlberg T, Eloranta S, Hyväri H, Salminen E. Breast cancer patients receiving postoperative radiotherapy: distress, depressive symptoms and unmet needs of psychosocial support. Radiother Oncol. 2011;100(2):299-303.

42. Kawase E, Karasawa K, Shimotsu S, et al. Estimation of anxiety and depression in patients with early stage breast cancer before and after radiation therapy. Breast Cancer. 2012;19(2):147-152.

43. Torres MA, Pace TW, Liu T, et al. Predictors of depression in breast cancer patients treated with radiation: role of prior chemotherapy and nuclear factor kappa B. Cancer. 2013;119(11):1951-1959.

44. Northouse L, Kershaw T, Mood D, Schafenacker A. Effects of a family intervention on the quality of life of women with recurrent breast cancer and their family caregivers. Psycho-oncology. 2005;14(6):478-491.

45. So WK, Marsh G, Ling WM, et al. The symptom cluster of fatigue, pain, anxiety, and depression and the effect on the quality of life of women receiving treatment for breast cancer: a multicenter study. Oncol Nurs Forum. 2009;36(4):E205-E214.
46. Tasmuth T, Estlanderb AM, Kalso E. Effect of present pain and mood on the memory of past postoperative pain in women treated surgically for breast cancer. Pain. 1996;68(2-3):343-347.

47. Breivik H, Cherny N, Collett B, et al. Cancer-related pain: a panEuropean survey of prevalence, treatment, and patient attitudes. Ann Oncol. 2009;20(8):1420-1433.

48. Khan F, Amatya B, Pallant JF, Rajapaksa I. Factors associated with long-term functional outcomes and psychological sequelae in women after breast cancer. Breast. 2012;21(3):314-320.

49. Giese-Davis J, Collie K, Rancourt KMS, Neri E, Kraemer HC, Spiegel D. Decrease in depression symptoms is associated with longer survival in patients with metastatic breast cancer: a secondary analysis. J Clin Oncol. 2011;29(4):413-420.

50. Mullan F. Seasons of survival: reflections of a physician with cancer. N Engl J Med. 1985;313(4):270-273.

\section{Dovepress}

\section{Publish your work in this journal}

Neuropsychiatric Disease and Treatment is an international, peerreviewed journal of clinical therapeutics and pharmacology focusing on concise rapid reporting of clinical or pre-clinical studies on a range of neuropsychiatric and neurological disorders. This journal is indexed on PubMed Central, the 'PsycINFO' database and CAS, and is the official journal of The International Neuropsychiatric Association (INA). The manuscript management system is completely online and includes a very quick and fair peer-review system, which is all easy to use. Visit http://www.dovepress.com/testimonials.php to read real quotes from published authors. 